\title{
Growth Hormone Treatment in Children with Short Stature Born Small for Gestational Age: 5-Year Results of a Randomized, Double-Blind, Dose-Response Trial**
}

\author{
THEO SAS, WOUTER DE WAAL, PAUL MULDER, MIEKE HOUDIJK, \\ MAARTEN JANSEN, MAARTEN REESER, AND ANITA HOKKEN-KOELEGA
}

Department of Pediatrics, Division of Endocrinology, Sophia Children's Hospital/Erasmus University (Th.S., W.d.W., A.H.-K.), 3015 GJ Rotterdam; Institute of Epidemiology and Biostatistics, Erasmus University (P.M.), 3015 GJ Rotterdam; Academic Hospital of Free University (M.H.), 1081 HV Amsterdam; Wilhelmina Children's Hospital (M.J.), 3584 EA Utrecht; and Juliana Children's Hospital (M.R.), 2566 ER The Hague, The Netherlands

\begin{abstract}
The growth-promoting effect of continuous GH treatment was evaluated over 5 yr in 79 children with short stature (height SD score, less than -1.88) born small for gestational age (SGA; birth length SD score, less than -1.88). Patients were randomly and blindly assigned to 1 of $2 \mathrm{GH}$ dosage groups ( $3 \mathrm{vs}$. $6 \mathrm{IU} / \mathrm{m}^{2}$ body surface-day). GH deficiency was not an exclusion criterium. After $5 \mathrm{yr}$ of GH treatment almost every child had reached a height well within the normal range for healthy Dutch children and in the range of their target height SD score. Only in children who remained prepubertal during the study period was the 5-yr increase in height SD score (HSDS) for chronological age significantly higher in the study group receiving 6 com-
\end{abstract}

pared to $3 \mathrm{IU} \mathrm{GH} / \mathrm{m}^{2}$-day. Remarkably, the 5 -yr increment in HSDS for chronological age was not related to spontaneous GH secretion, maximum GH levels after provocation, or baseline insulin-like growth factor I levels. GH treatment was associated with an acceleration of bone maturation regardless of the GH dose given. The HSDS for bone age and predicted adult height increased significantly. GH treatment was well tolerated.

In conclusion, our 5-yr data show that long term continuous GH treatment at a dose of 3 or $6 \mathrm{IU} / \mathrm{m}^{2}$.day in short children born SGA results in a normalization of height during childhood followed by growth along the target height percentile. (J Clin Endocrinol Metab 84: $3064-3070,1999$
$\mathrm{S}^{\mathrm{H}}$ HORT STATURE in children born small for gestational age (SGA) is a well known phenomenon. Although postnatal catch-up growth occurs in most of the SGA newborns, about $15 \%$ of these children fail to show catch-up growth $(1,2)$. They present with a height deficit during childhood that in almost all cases results in short adult stature (3-5). The mechanism of the stunted postnatal growth in short children born SGA is poorly understood. It has been previously shown that disturbances in the GH/insulin-like growth factor I (IGF-I) axis may account for some of the growth retardation; up to $60 \%$ of the short children born SGA have GH secretory abnormalities and/or reduced levels of IGFs (6-12). GH treatment in these children has been explored from the early 1970s $(13,14)$. Initial data were disappointing, probably due to the low dose and frequency of GH administration. Recent short term studies have shown that daily administration of recombinant human GH therapy in varying dosages accelerates growth significantly in short children born SGA $(7,15-22)$.

Received January 11, 1999. Revision received May 6, 1999. Accepted May 19, 1999.

Address all correspondence and requests for reprints to: Th. C. J. Sas, M.D., Sophia Children's Hospital, Department of Pediatrics, Division of Endocrinology, Dr. Molewaterplein 60, 3015 GJ Rotterdam, The Netherlands.

* This work was supported by Novo Nordisk A/S (Bagsvaerd, Denmark). Preliminary 2-yr results were presented in the thesis of Wouter de Waal (Erasmus University, Rotterdam, The Netherlands, 1996). Preliminary 5-yr results have been presented at the European Society for Pediatric Endocrinology, Florence, Italy, September 1998
To assess whether GH treatment will also improve linear growth over the long term as well as adult height, we started a randomized, double blind, dose-response multicenter trial with continuous GH treatment in 79 prepubertal children with short stature born SGA. We now report a 5-yr analysis comparing the effects of 2 doses of GH (3 vs. $6 \mathrm{IU} / \mathrm{m}^{2}$ body surface·day).

\section{Subjects and Methods}

\section{Study group}

Seventy-nine prepubertal short children born SGA were included after meeting the following criteria: 1) birth length SD score below -1.88 (that is, less than the third percentile) for gestational age according to the standards of Usher and McLean (23); 2) chronological age (CA) between 3-11 yr in boys and 3-9 yr in girls at the start of the study; 3) height SD score for $\mathrm{CA}\left(\mathrm{HSDS}_{\mathrm{CA}}\right)$ below -1.88 according to Dutch references (24); 4) height velocity SD score for CA (HVSDS) of zero or less $(24,25)$, to exclude children presenting spontaneous catch-up growth; 5) prepubertal stage, defined as Tanner breast stage I for girls and testicular volume less than $4 \mathrm{~mL}$ for boys $(26)$; 6) uncomplicated neonatal period that is without signs of severe asphyxia (defined as an Apgar score $<3$ after $5 \mathrm{~min}$ ), without sepsis neonatorum and without long term complications of respiratory ventilation, such as bronchopulmonary dysplasia. Exclusion criteria were endocrine or metabolic disorders, chromosomal disorders, growth failure caused by other disorders or syndromes (emotional deprivation, severe chronic illness, or chondrodysplasia), and previous or present use of drugs that could interfere with GH treatment. Patients with Silver-Russell syndrome (SRS), however, were included in this study. GH deficiency was not an exclusion criterium.

Four centers in The Netherlands participated in the study. The study was approved by the ethics committee of each participating center. 
Written informed consent was obtained from the parents or custodians of each child.

\section{Study design}

Before GH treatment, 40 of the 79 children underwent a 24-h plasma GH profile, as described previously (6). To stratify for the spontaneous $\mathrm{GH}$ secretion during the 24-h GH profile, the total group of 79 children was divided into 3 groups: normal profile, GH-insufficient profile (area under the curve, $<90 \mu \mathrm{g} / \mathrm{L} \cdot 24 \mathrm{~h}$; mean GH, $<2.0 \mu \mathrm{g} / \mathrm{L}$ ), and no profile performed. After stratification for spontaneous GH secretion during the 24-h GH profile and for CA, all children were randomly and blindly assigned to 1 of $2 \mathrm{GH}$ dosage groups: group $\mathrm{A}, 3 \mathrm{IU} / \mathrm{m}^{2}$ body surface-day; or group B, $6 \mathrm{IU} / \mathrm{m}^{2}$ body surface-day ( $\sim 0.1$ or $0.2 \mathrm{IU} /$ $\mathrm{kg} \cdot$ day, respectively). Biosynthetic GH (r-hGH Norditropin, Novo Nordisk A /S, Bagsvaerd, Denmark) was given sc once daily at bedtime with a pen injection system (Nordiject 24). Every 3 months the total GH dose was adjusted to the calculated body surface. The study was kept double blind by using an equal volume of a reconstituted preparation. Criteria to discontinue GH treatment were height velocity $(\mathrm{HV})$ below $0.5 \mathrm{~cm}$ over the last 6 months and/or bone age of $15 \mathrm{yr}$ or more for girls and of $16.5 \mathrm{yr}$ or more for boys.

\section{Growth evaluation}

Height $(\mathrm{H})$ was measured at baseline and subsequently every 3 months, according to the method of Cameron (27) using a Harpenden stadiometer (Holtain, Ltd., Crymmyth, UK). Four measurements per visit were made by two trained observers (W.d.W. and later on Th.S.), and the mean was used for the analysis. Height was expressed as the SD score for CA (HSDS ${ }_{\mathrm{CA}}$ ) (24). Target height $(\mathrm{TH})$ was adapted from Dutch reference data with the addition of $3 \mathrm{~cm}$ for a secular trend: $1 / 2 \times\left(\mathrm{H}_{\mathrm{father}}\right.$ $\left.+\mathrm{H}_{\text {mother }}+12\right)+3$ for boys and $1 / 2 \times\left(\mathrm{H}_{\text {father }}+\mathrm{H}_{\text {mother }}-12\right)+3$ for girls (24). TH and body mass index (BMI) were expressed as SD scores using Dutch references (24). Bone age (BA) was determined by one investigator (Th.S.) according to Tanner and Whitehouse radius, ulna, and short bones score $\left(\mathrm{BA}_{\mathrm{RUS}}\right)$ (28). Bone maturation was expressed as the ratio of the change in $\mathrm{BA}$ to the change in $\mathrm{CA}(\triangle \mathrm{BA} / \triangle \mathrm{CA})$. The HSDS for BA $\left(\mathrm{HSDS}_{\mathrm{BA}}\right)$ and adult height prediction according to the Tanner and Whitehouse prediction method (TW2) (28) were used as indexes of adult height prognosis. Pubertal stages were assessed by the same two investigators according to the method of Tanner (26), using an orchidometer in boys.

\section{Biochemical parameters}

Before treatment, a standard arginine tolerance test was performed (6). A standard oral glucose tolerance test (OGTT) was performed at baseline and after $1 \mathrm{yr}$ of GH treatment (29). Additional blood samples were taken at the start of the study and subsequently every year for determination of IGF-I and hemoglobin $\mathrm{A}_{1 \mathrm{c}}$ levels. IGF-binding protein-3 (IGFBP-3) was determined at start of the study and after the first and second years and after the fifth year of GH treatment. After centrifugation, all samples were frozen $(-20 \mathrm{C})$ until assayed.

\section{Hormone assays}

The RIA measurements of plasma GH, IGF-I, IGFBP-3, and insulin were performed as described previously (30-33). All measurements were performed in the same laboratories. As levels of both IGF-I and IGFBP-3 are dependent on age and sex, values were transformed to SD scores using reference values for healthy children determined in the same laboratory (34).

\section{Statistical analyses}

Results are expressed as the mean $\pm \mathrm{SD}$, unless indicated otherwise. Differences between groups were tested using Student's $t$ tests. Differences between points in time were tested by paired Student's $t$ tests. To study the relation between the growth response variables (increment in HSDS $_{\mathrm{CA}}$ after $5 \mathrm{yr}$ ) and baseline parameters, multiple linear regression analyses, adjusted for GH dosage group, were performed. For each possible predictive factor, separate analyses were performed. Possible predictive baseline factors were: $\mathrm{CA}, \mathrm{BA}_{\mathrm{RUS}}, \mathrm{BA}$ delay $(\mathrm{CA}-\mathrm{BA}), \mathrm{TH}$ sD score, IGF-I sD score, pretreatment HVSDS, maximum GH value during the GH provocation test, and the characteristics of the 24-h GH profiles established at the start of the study (6). A subgroup analysis of prepubertal growth was performed in the group of children who remained prepubertal during the entire study period. Girls with Tanner breast stage I and boys with a testis volume of $6 \mathrm{~mL}$ or less during the 5 -yr study period were included in this analysis of prepubertal growth. $P<0.05$ was considered significant.

As the study remains double blind until final height is reached, statistical analysis was performed by an independent statistician (P.M.); therefore, data are only expressed as the mean \pm SD.

\section{Results}

\section{Clinical data, growth, and bone maturation}

Table 1 lists the baseline clinical data of the 79 children. Both GH dosage groups had similar initial characteristics. Seven children had SRS. Five children dropped out of the study for the following reasons. Three children were no longer motivated to inject GH daily after 15, 45, and 51 months of GH treatment, respectively, despite ongoing catch-up growth with GH treatment in 2 of the 3 children. One girl dropped out of the study because of treatment for early puberty after 27 months of GH treatment. In 1 boy, GH treatment was discontinued after 27 months because of signs of GH insensitivity. During GH treatment his IGF-I levels and HV did not increase despite good compliance with treatment. As these 5 children were lost to follow-up after discontinuation of $\mathrm{GH}$, their data were not included in the analysis.

Figure 1 shows the height at baseline as well as the height after $5 \mathrm{yr}$ of GH treatment. During the 5-yr study period, onset of puberty was observed in 47 of the 74 children. The mean CA at the onset of puberty did not differ between the GH dosage groups (in girls, $10.5 \pm 0.9$ vs. $11.0 \pm 1.1 \mathrm{yr}$; in boys, $11.9 \pm 0.9$ vs. $11.6 \pm 0.6$ ) and was apparently within the normal range. One male adolescent discontinued GH treatment after 54 months because of satisfaction with the height achieved $(165.3 \mathrm{~cm})$. All other children were still growing and receiving $\mathrm{GH}$ treatment. As the design of the study is still double blind, in these figures no separate growth diagrams were made for the $2 \mathrm{GH}$ dosage groups. After $5 \mathrm{yr}$, almost every child had achieved a height well within the normal range for healthy Dutch children.

Figure 2 shows the $\mathrm{HSDS}_{\mathrm{CA}}$ at baseline and throughout the 5 -yr study period. After $5 \mathrm{yr}$ of $\mathrm{GH}$ treatment, the mean HSDS $_{\mathrm{CA}}$ in both GH dosage groups have significantly increased compared to baseline values $(P<0.001)$ and in

TABLE 1. Baseline clinical data

\begin{tabular}{lcc}
\hline & $\begin{array}{c}\text { Group A } \\
\left(3 \mathrm{IU} / \mathrm{m}^{2} \cdot \text { day; } \mathrm{n}=41\right)\end{array}$ & $\begin{array}{c}\text { Group B } \\
\left(6 \mathrm{IU} / \mathrm{m}^{2} \cdot \text { day; } \mathrm{n}=38\right)\end{array}$ \\
\hline Male/female & $31 / 10$ & $21 / 17$ \\
Gestational age (weeks) & $37.3 \pm 3.2$ & $36.0 \pm 4.1$ \\
Birth length sD score & $-3.6 \pm 1.4$ & $-3.7 \pm 1.7$ \\
Birth wt SD score & $-2.6 \pm 1.2$ & $-2.6 \pm 1.0$ \\
Chronological age $(\mathrm{yr})$ & $7.3 \pm 2.1$ & $7.2 \pm 2.4$ \\
Bone age (RUS; yr) & $6.6 \pm 2.4$ & $6.7 \pm 2.9$ \\
Ht SD score & $-3.0 \pm 0.7$ & $-3.1 \pm 0.7$ \\
Ht velocity SD score & $-0.7 \pm 1.1$ & $-1.2 \pm 1.3$ \\
Target ht SD score & $-1.0 \pm 0.9$ & $-0.5 \pm 0.9$ \\
\hline
\end{tabular}

Values are the mean \pm SD. 

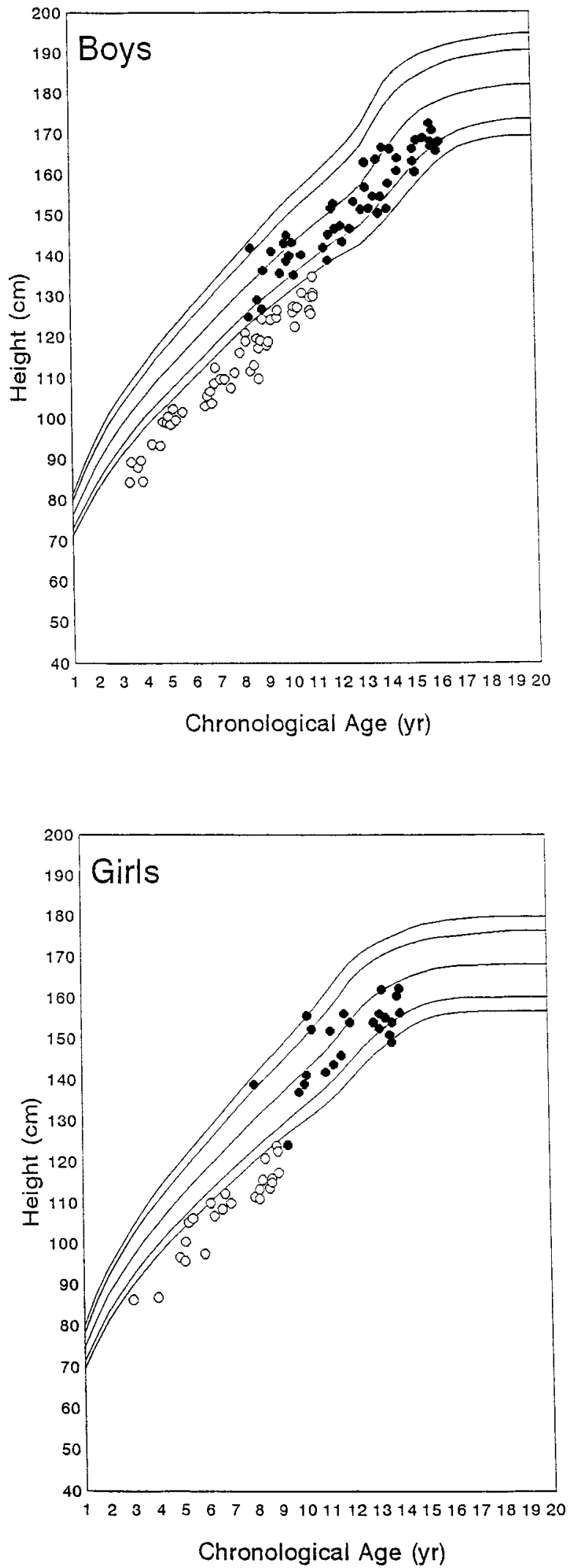

FIG. 1. Individual heights at start of the study and after 5 yr of GH treatment. Reference curves for healthy Dutch children (P3, P10, P50, P90, and P97) are given.

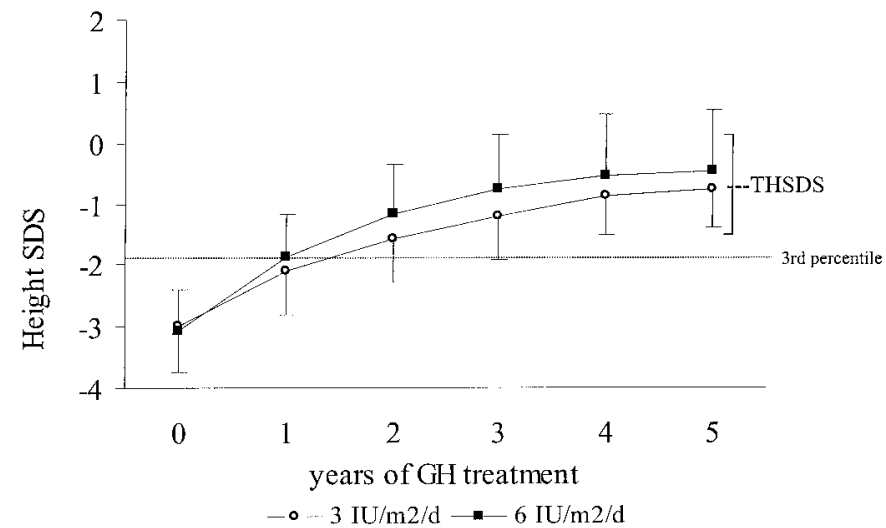

FIG. 2. Mean ( $\pm \mathrm{SD}) \mathrm{HSDS}_{\mathrm{CA}}$ for both $\mathrm{GH}$ dosage groups during $5 \mathrm{yr}$ of GH treatment. The TH SD score $( \pm 1 \mathrm{SD})$ is indicated.

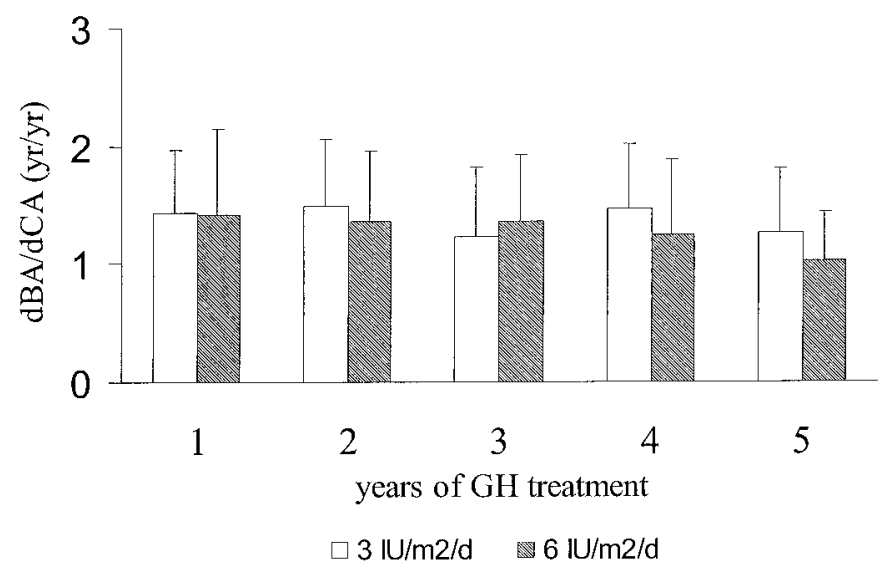

Fig. 3. Mean $( \pm \mathrm{SD})$ ratio $[\Delta \mathrm{BA}$ (years)/ $\Delta \mathrm{CA}$ (years)] per yr for both $\mathrm{GH}$ dosage groups during $5 \mathrm{yr}$ of $\mathrm{GH}$ treatment.

conformity with the target height SD score. Although the 5-yr increase in $\mathrm{HSDS}_{\mathrm{CA}}$ was higher in group B (2.6 \pm 0.9$)$ than in group $\mathrm{A}(2.2 \pm 0.6)$, the difference was not statistically significant $(P=0.057)$. The increment in $\mathrm{HSDS}_{\mathrm{CA}}$ was not different between the seven children with SRS and those without SRS (data not shown).

Figure 3 shows the $\triangle \mathrm{BA} / \triangle \mathrm{CA}$ ratio per yr throughout the 5 -yr study period. The mean $\Delta \mathrm{BA} / \Delta \mathrm{CA}$ ratio per yr was significantly higher than 1 for both GH dosage groups (1.4 \pm 0.2 and $1.3 \pm 0.2$, respectively; $P<0.001$ ). No significant difference in bone maturation was found between the two $\mathrm{GH}$ dosage groups. At baseline, mean $\mathrm{BA}_{\mathrm{RUS}}$ retardation was $0.6 \pm 1.0 \mathrm{yr}$, whereas after $5 \mathrm{yr}$ of $\mathrm{GH}$ treatment, mean $\mathrm{BA}_{\mathrm{RUS}}$ was advanced by $1.0 \pm 1.1 \mathrm{yr}$.

After 5 yr of GH treatment, HSDS $_{B A}$ increased significantly compared to baseline $(P \leq 0.001)$. The increase was significantly higher in group B (from $-2.4 \pm 1.0$ to $1.2 \pm 0.8$ ) compared to that in group A (from $-2.1 \pm 1.1$ to $1.5 \pm 0.8$; $P=0.004$ ).

In the subanalysis on prepubertal growth ( $\mathrm{n}=23$ in group $A ; n=16$ in group B), the increment in $\mathrm{HSDS}_{\mathrm{CA}}$ was significantly increased in both $\mathrm{GH}$ dosage groups $(P<0.001$; Fig. 4). The increase in $\mathrm{HSDS}_{\mathrm{CA}}$ was significantly higher in group $\mathrm{B}(3.30 \pm 0.73)$ than in group $\mathrm{A}(2.35 \pm 0.51 ; P<0.001)$. The mean $\triangle \mathrm{BA} / \triangle \mathrm{CA}$ ratio per yr was significantly higher 


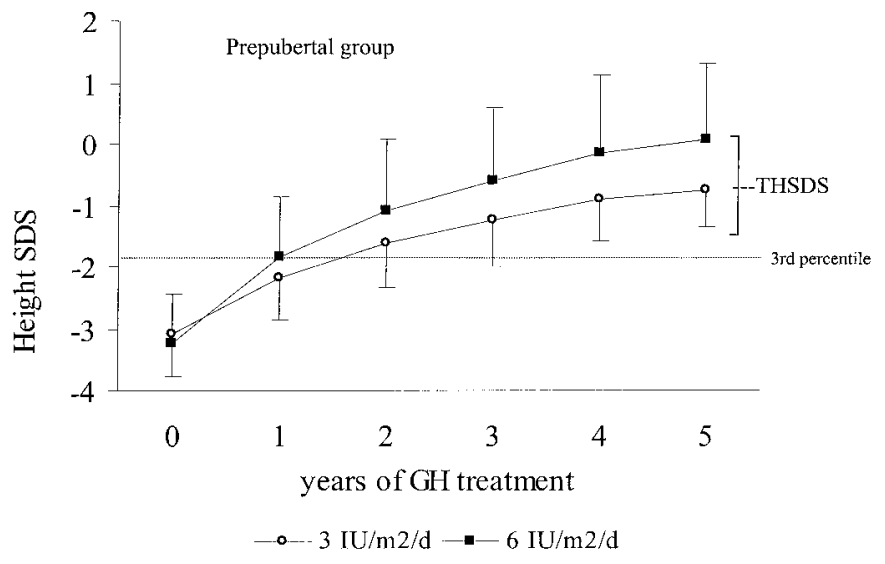

FIG. 4. Mean ( $\pm \mathrm{SD}) \mathrm{HSDS}_{\mathrm{CA}}$ for both $\mathrm{GH}$ dosage groups during $5 \mathrm{yr}$ of GH treatment in the children who remained prepubertal during the study period. The TH SD score ( $\pm 1 \mathrm{SD})$ is indicated.

than 1 for both $\mathrm{GH}$ dosage groups $(1.39 \pm 1.17$ and $1.37 \pm$ 0.22 , respectively; $P<0.001$ ), without significant differences between the two groups. HSDS $_{\mathrm{BA}}$ increased significantly compared to baseline $(P<0.05)$. The increase in $\mathrm{HSDS}_{\mathrm{BA}}$ was significantly higher in group $\mathrm{B}$ (from $-2.06 \pm 1.17$ to $-0.88 \pm$ 0.93 ) compared to that in group A (from $-1.86 \pm 1.11$ to $-1.49 \pm 0.89 ; P=0.02)$. The increase in predicted adult height after $5 \mathrm{yr}$ of GH treatment was $9.1 \pm 2.8 \mathrm{~cm}$ in group $A$ and $14.0 \pm 5.5 \mathrm{~cm}$ in group B, being significantly increased compared to baseline in both $\mathrm{GH}$ dosage groups $(P<0.005)$ and significantly higher in group $\mathrm{B}$ than in group $\mathrm{A}(P=$ $0.02)$.

\section{$B M I$}

At baseline, the BMI sD score (BMI-SDS) was $-1.2 \pm 1.3$ in group $A$ and $-1.2 \pm 1.1$ in group $B$, being significantly lower than zero $(P<0.001)$. After 5 yr of GH treatment, BMI-SDS was significantly increased to $-0.3 \pm 1.2$ in group $\mathrm{A}$ and to $-0.2 \pm 0.8$ in group $\mathrm{B}(P<0.001)$. The increase in BMI-SDS was not significantly different between the two GH dosage groups.

\section{GH, IGF-I, and IGFBP-3}

The results of the 24-h plasma GH profiles at baseline have been described previously (6). The mean \pm SD maximum serum GH concentration during the arginine tolerance test at baseline was not significantly different between the two GH dosage groups (11.2 \pm 6.3 vs. $14.0 \pm 6.3 \mu \mathrm{g} / \mathrm{L})$. In 27 children, the maximal GH peak was below $10 \mu \mathrm{g} / \mathrm{L}$.

Table 2 shows the IGF-I and IGFBP-3 sD score at baseline and during $5 \mathrm{yr}$ of GH treatment. The baseline IGF-I sD score was significantly lower than zero. During GH treatment, the IGF-I sD score was significantly higher than baseline at each point in time for both GH dosage groups. The IGF-I sD score was significantly higher in group B compared to group A during the first $3 \mathrm{yr}$. Thereafter, this difference was no longer statistically significant. The mean baseline IGFBP-3 sD score was significantly lower than zero. During the first year of GH treatment, the IGFBP-3 concentrations normalized, and after $5 \mathrm{yr}$, the IGFBP-3 SD score was significantly higher than zero for both GH dosage groups. The IGFBP-3 sD score after $5 \mathrm{yr}$
TABLE 2. Mean ( \pm SD) IGF-I and IGFBP-3 SD scores

\begin{tabular}{lcc}
\hline & $\begin{array}{c}\text { Group A } \\
\left(3 \mathrm{IU} / \mathrm{m}^{2} \cdot \text { day }\right)\end{array}$ & $\begin{array}{c}\text { Group B } \\
\left(6 \mathrm{IU} / \mathrm{m}^{2} \cdot \text { day }\right)\end{array}$ \\
\hline IGF-I sD score & & \\
Baseline & $-1.2 \pm 1.2^{a}$ & $-0.9 \pm 1.0^{a}$ \\
$1 \mathrm{yr}$ & $1.2 \pm 1.1^{a}$ & $1.9 \pm 1.1^{a, b}$ \\
$2 \mathrm{yr}$ & $1.2 \pm 1.0^{a}$ & $1.9 \pm 1.2^{a, c}$ \\
$3 \mathrm{yr}$ & $1.4 \pm 1.0^{a}$ & $2.0 \pm 1.2^{a, c}$ \\
$4 \mathrm{yr}$ & $1.8 \pm 0.8^{a}$ & $2.0 \pm 1.2^{a}$ \\
$5 \mathrm{yr}$ & $1.7 \pm 0.7^{a}$ & $2.0 \pm 0.9^{a}$ \\
IGFBP-3 sD score & & \\
Baseline & $-1.7 \pm 1.3^{a}$ & $-1.3 \pm 1.1^{a}$ \\
$1 \mathrm{yr}$ & $0.2 \pm 1.2$ & $0.5 \pm 1.1^{d}$ \\
$2 \mathrm{yr}$ & $0.0 \pm 1.2$ & $0.2 \pm 1.0$ \\
$5 \mathrm{yr}$ & $1.0 \pm 0.8^{a}$ & $1.2 \pm 1.0^{a}$ \\
\hline
\end{tabular}

${ }^{a}$ Significantly different from zero, $P<0.001$.

${ }^{b}$ Significantly higher in the group receiving 6 than in the group receiving $3 \mathrm{IU} / \mathrm{m}^{2} \cdot$ day, $P=0.01$.

${ }^{c}$ Significantly higher in the group receiving 6 than in the group receiving $3 \mathrm{IU} / \mathrm{m}^{2} \cdot$ day, $P<0.05$.

${ }^{d}$ Significantly different from zero, $P=0.021$.

of GH treatment was not significantly different between groups $\mathrm{A}$ and $\mathrm{B}$.

\section{Predictors for growth response}

After adjustment for GH dosage group, the 5-year increase in $\mathrm{HSDS}_{\mathrm{CA}}$ correlated negatively with baseline CA $(\beta=$ $-0.216 ; P<0.001)$ and baseline $\mathrm{BA}_{\mathrm{RUS}}(\beta=-0.173 ; P<$ $0.001)$. The 5 -yr change in $\mathrm{HSDS}_{\mathrm{CA}}$ was not significantly related to the TH SD score, baseline BA delay, pretreatment HVSDS, baseline IGF-I SD score, mean maximal plasma GH response during arginine tolerance test, or characteristics of the 24-h GH profiles established at the start of the study (6). In addition, no difference in the 5 -yr increment in $\mathrm{HSDS}_{\mathrm{CA}}$ was found between the children with GH deficiency and those with normal GH levels.

\section{Safety}

Treatment was well tolerated, and no adverse events were detected that were considered to be drug related. In both GH dosage groups, the mean fasting glucose level and area under the curve for glucose during OGTT did not significantly change during $1 \mathrm{yr}$ of GH treatment compared to baseline values. In contrast, the mean fasting insulin levels increased significantly in both GH dosage groups after $1 \mathrm{yr}$ of $\mathrm{GH}$ treatment, from 6.4 to $7.6 \mathrm{mU} / \mathrm{L}$ and from 4.9 to $8.4 \mathrm{mU} / \mathrm{L}$ for groups A and $\mathrm{B}$, respectively $(P<0.01)$. In addition, the area under the curve for insulin during OGTT was significantly higher after $1 \mathrm{yr}$ of $\mathrm{GH}$ treatment compared to the baseline $(P<0.001)$, from 1433 at baseline to $2101 \mathrm{mU} / \mathrm{L} \cdot 1$ $\mathrm{h}$ after $1 \mathrm{yr}$ for group A and from 1161 to $2634 \mathrm{mU} / \mathrm{L} \cdot 1 \mathrm{~h}$ for group $\mathrm{B}$, however, without a significant difference between the two $\mathrm{GH}$ dosage groups. Hemoglobin $\mathrm{A}_{1 \mathrm{c}}$ levels remained within the normal range, and none of the children developed diabetes mellitus.

\section{Discussion}

Our study shows that long term continuous GH treatment ( 3 vs. $6 \mathrm{IU} / \mathrm{m}^{2}$.day) in children with short stature born SGA results in a normalization of height during childhood, fol- 
lowed by growth along the target height percentile. The difference in gain in $\mathrm{HSDS}_{\mathrm{CA}}$ between the $\mathrm{GH}$ dosage groups was not statistically significant. Only in children who remained prepubertal during the study was the mean gain in $\mathrm{HSDS}_{\mathrm{CA}}$ after $5 \mathrm{yr}$ of GH treatment significantly greater in those treated with 6 compared to $3 \mathrm{IU} / \mathrm{m}^{2} \cdot$ day. Both $\mathrm{GH}$ dosage groups reached their target height SD score well within $5 \mathrm{yr}$ of GH treatment, indicating that long term GH treatment with a lower $\mathrm{GH}$ dose of $3 \mathrm{IU} / \mathrm{m}^{2}$.day is also able to normalize the height of short children born SGA.

Most controlled trials have shown a beneficial effect of $\mathrm{GH}$ treatment over a period of 2-3 yr in comparison with a randomized untreated group of children born SGA for 1 or $2 \mathrm{yr}$. The untreated children did not show any spontaneous catch-up growth, indicating that they are destined to remain short $(18,20,21)$. For our long term study, a randomized controlled trial with an untreated group until adult height was reached was considered unethical by several ethics committees. Therefore, a dose-response design comparing two GH dosages ( 3 and $6 \mathrm{IU} / \mathrm{m}^{2}$.day) was chosen to evaluate the long term use of continuous GH treatment.

Our 5-yr results consolidate the previously described effects of short term GH treatment in short children born SGA (18-22). In the 3-yr study reported by Boguszewski et al., daily $\mathrm{GH}$ dosages ( 3 and $6 \mathrm{IU} / \mathrm{m}^{2}$ ) similar to those in our study were used. Interestingly, the GH dose-dependent 3-yr increase in $\mathrm{HSDS}_{\mathrm{CA}}$ in prepubertal children was almost identical in both studies (21). A meta-analysis of four European trials showed that the 4-yr growth response was similar between continuous $\mathrm{GH}$ use $\left(3 \mathrm{IU} / \mathrm{m}^{2}\right.$.day for $4 \mathrm{yr}$ ) and discontinuous GH use $\left(6 \mathrm{IU} / \mathrm{m}^{2}\right.$.day for $2 \mathrm{yr}$, followed by 2 yr without $\mathrm{GH}$ ) (22), suggesting that the cumulative $\mathrm{GH}$ dose received and not the daily GH dose determines the growth response. All studies demonstrate that $\mathrm{GH}$ treatment induces an acceleration in linear growth in short children born SGA. In addition, our 5-yr study shows that continuous GH treatment can normalize height and is followed by a persistent growth within the normal height range.

Comparing our growth results with those of other $\mathrm{GH}-$ treated patient groups receiving long term $\mathrm{GH}$ treatment, the gain in height in short children born SGA is comparable with that in GHD patients with a GH dose that is slightly higher than the conventional GH dose (2 IU/ $\mathrm{m}^{2}$.day) (35).

In some previous short term studies and in the present study, bone maturation was accelerated compared to that in untreated short children born SGA and compared to healthy children, respectively $(18,20,22)$. However, it was remarkable that during the 5-yr treatment period, bone maturation in the total group as well as in the children who remained prepubertal during the study period appeared to be independent of the given GH dose, whereas no progressive acceleration of bone maturation was found. Previous reports have demonstrated a spontaneous acceleration of bone maturation from the age of 6-10 yr in untreated children with short stature born SGA $(3,36,37)$. Therefore, the acceleration of bone maturation seen in GH-treated short children born SGA may be partly explained by the effects of GH treatment, but may also be explained by the spontaneous acceleration of bone maturation observed in untreated SGA children.

Data on final height are very limited. Therefore, an indi- cation of final height is often given by the change in HSDS $_{\mathrm{BA}}$ and the predicted adult height, according to the Tanner and Whitehouse prediction method, during GH treatment. In our study, $\mathrm{HSDS}_{\mathrm{BA}}$ and predicted adult height increased significantly after $5 \mathrm{yr}$ of $\mathrm{GH}$ treatment, in conformity with the results described in short term studies $(20,22)$. Thus, the gain in height outweighs the faster bone maturation. However, we realize that both prediction methods have limitations; therefore, data on adult height have to substantiate our results. Only 2 studies reported data on final height in relatively small numbers of patients $(38,39)$. One study reported data from a pharmaceutical registration database showing that 16 SGA patients, treated with GH at a median daily GH dose of approximately $3 \mathrm{IU} / \mathrm{m}^{2}$ until near adult height, achieved an adult stature that was $1.0 \mathrm{SD}$ score greater than the pretreatment $\mathrm{HSDS}_{\mathrm{CA}}$ (38). However, in these patients the median age at start of treatment was $12.7 \mathrm{yr}$. Preliminary data from the study by Albanese et al. demonstrated that in 12 GH-treated children with short stature born SGA, GH treatment with approximately $4 \mathrm{IU} / \mathrm{m}^{2}$.day starting at a mean age of $7.6 \mathrm{yr}$ significantly improved final height. Although $\mathrm{HSDS}_{\mathrm{BA}}$ did not improve throughout the study, the HSDS $_{\mathrm{CA}}$ had increased from -2.9 at baseline to -1.5 at final height (39).

Some studies reported earlier onset of puberty in untreated short children born SGA $(36,37)$. The question arose as to whether GH could further advance the timing of puberty and consequently reduce the growth period. In our study the mean pubertal onset seemed not to be advanced by GH treatment (girls, 10.8 yr; boys, 11.8 yr). However, longer follow-up is required to establish whether all of our children will start puberty at an appropriate age and whether the overall duration of puberty is altered.

As described in other studies, the variability in growth response to GH treatment was considerable. For that reason, we looked for clinical predictors of the growth response to $\mathrm{GH}$ treatment. The increase in $\mathrm{HSDS}_{\mathrm{CA}}$ over $5 \mathrm{yr}$ of treatment was negatively related to baseline $\mathrm{CA}$ and $\mathrm{BA}$; the younger the child at baseline, the better the 5-yr increase in $\mathrm{HSDS}_{\mathrm{CA}}$. In contrast, neither the height of the parents, the pretreatment $\mathrm{HV}$, nor the baseline BA retardation were related to the 5-yr increment in height.

The etiology underlying the insufficient spontaneous catch-up growth in short children born SGA is poorly understood. Findings in previous studies (6-12) and in our study suggest that disturbances in the GH/IGF-I axis play a role in the absence of spontaneous catch-up growth. However, before treatment, we found no clear relation between the GH secretory status and spontaneous growth (6). To study the relation between the baseline parameters of the GH secretion status and the growth response to GH treatment, we included, in contrast to other prospective studies, patients regardless of their GH secretion. We found that the maximum GH levels during the provocation tests before the start of the GH treatment were not significantly related to the growth response. Two previous studies also found no differences in growth response to GH treatment between SGA children who were GH deficient and those who were not (35, 40). In addition, our study showed that neither the IGF-I levels at baseline nor the GH levels during the 24-h plasma 
GH profile test were significantly related to the growth response. Thus, although the stunted growth in short stature children born SGA may be partly explained by disturbances in the GH/IGF-I axis, the growth-promoting effect of GH treatment at a dose of 3-6 IU $/ \mathrm{m}^{2}$.day seems to be independent of the baseline GH/IGF-I status.

It is well known that many short children born SGA are lean and have a lack of appetite. In the present study, we did not systematically investigate a possible change in the appetite of the children. Several parents, however, mentioned that the children had better appetite and food intake after the start of the GH treatment. Although we do not know the natural development of body mass in short children born SGA during childhood, it is remarkable that the normalization of height during GH treatment was accompanied by a normalization of the BMI. We may speculate that the anabolic effect of GH treatment has a positive influence on the food intake of the child and that this plays an additional role in the catch-up growth of short children born SGA.

Our study showed that the height gain after 5 yr of GH treatment with $6 \mathrm{IU} / \mathrm{m}^{2}$-day was only statistically significant higher than that after treatment with $3 \mathrm{IU} / \mathrm{m}^{2} \cdot$ day in the children who remained prepubertal during the study period. In addition, this difference was relatively modest, suggesting that near-maximal GH effects in SGA children are reached in this dose range. Follow-up until adult height is needed to assess whether the higher GH dose results in a significantly better improvement of adult height. Therefore, we will continue our double blind, dose-response study until all children have attained adult height.

In conformity with other studies (18-22), tolerance to GH treatment was good. No adverse events were detected that were GH related. In our study, 1-yr GH treatment resulted in a significant rise in insulin levels, with normal glucose and glycosylated hemoglobin levels. SGA has been reported to be associated with an impairment in insulin sensitivity and with noninsulin-dependent diabetes mellitus in later life $(41,42)$. Further studies on the effects of long term GH treatment on carbohydrate metabolism are underway.

The most important aim of GH treatment in short children born SGA is a normalization of height and, consequently, an improvement of the psychosocial burden of being small in childhood as well as in adulthood. A 2-yr psychosocial evaluation in the children of our study showed a beneficial effect on behavioral and emotional problems and on the self-concept of the children $(43,44)$. Further psychosocial research will be performed to confirm this improvement.

In conclusion, our 5-yr data show that long term continuous GH treatment ( 3 or $6 \mathrm{IU} / \mathrm{m}^{2}$-day) in short children born SGA results in a normalization of height and subsequent growth along the TH percentile. The increase in height appears to be independent of the baseline GH/IGF-I status. Adult height prognosis and height SD score for BA increased significantly despite acceleration of bone maturation. The difference in growth response between the children receiving $6 \mathrm{IU} / \mathrm{m}^{2}$ daily and those receiving $3 \mathrm{IU} / \mathrm{m}^{2}$ was small and was only significant in the children who remained prepubertal during the study. Further studies should be directed at optimizing $\mathrm{GH}$ modalities, at establishing adult height results and long term safety data, and at determining the predictors indicating the small children born SGA who will benefit most from GH treatment.

\section{Acknowledgment}

Mrs. Janneke van Nieuwkasteele, research nurse, is greatly acknowledged for her assistance.

\section{References}

1. Albertsson-Wikland K, Karlberg J. 1994 Natural growth in children born small for gestational age with and without catch-up growth. Acta Paediatr Scand. 399(Suppl):64-70.

2. Hokken-Koelega ACS, de Ridder MAJ, van Lemmen RJ, den Hartog H, de Muinck Keizer-Schrama SMPF, Drop SLS. 1995 Children born small for gestational age: do they catch-up? Pediatr Res. 38:267-271.

3. Job JC, Rolland A. 1986 Histoire naturelle des retards de croissance á début intra-utérin. Arch Fr Pediatr. 43:301-306.

4. Chaussain JL, Colle M, Ducret JP. 1994 Adult height in children with prepubertal short stature secondary to intra uterine growth retardation. Acta Paediatr Scand. 399(Suppl):72-73.

5. Karlberg J, Albertsson-Wikland K. 1995 Growth in full-term small-for-gestational-age infants: from birth to final height. Pediatr Res. 38:733-739.

6. de Waal WJ, Hokken-Koelega ACS, Stijnen Th, de Muinck Keizer-Schrama Drop SLS. 1994 Endogenous and stimulated GH secretion, urinary GH excretion, and plasma IGF-I and IGF-II levels in prepubertal children with short stature after intrauterine growth retardation. Clin Endocrinol (Oxf). 41:621-630.

7. Albertsson-Wikland K. 1989 Growth hormone secretion and growth hormone treatment in children with intrauterine growth retardation. Acta Paediat Scand. 349(Suppl):35-41.

8. Rochiccioli P, Tauber M, Moisan V, Pinkowski C. 1989 Investigation of growth hormone secretion in patients with intrauterine growth retardation. Acta Paediatr Scand. 349(Suppl):42-46.

9. Stanhope R, Ackland F, Hamill G, Clayton J, Jones J, Preece MA, 1989 Physiological growth hormone secretion and response to growth hormone treatment in children with short stature and intra-uterine growth retardation. Acta Paediatr Scand. 349(Suppl):47-52.

10. Boguszewski M, Rosberg S, Albertsson-Wikland K. 1995 Spontaneous 24 hour growth hormone profiles in prepubertal small for gestational children. J Clin Endocrinol Metab. 80:2599-2606.

11. Boguszewski M, Jansson C, Rosberg S, Albertsson-Wikland K. 1996 Changes in serum insulin-like growth factor I (IGF-I) and IGF-binding protein-3 levels during growth hormone treatment in prepubertal short children born small for gestational age. J Clin Endocrinol Metab. 81:3902-3908.

12. Boguszewski CL, Jansson C, Boguszewski M, Rosberg S, Carlsson B, Albertsson-Wikland K. 1997 Increased proportion of circulating non-22-kilodalton growth hormone isoforms in short children: a possible mechanism for growth failure. J Clin Endocrinol Metab. 82:2944-2949.

13. Tanner JM, Whitehouse $\mathbf{R H}$, Hughes PCR, Vince FP. 1971 Effect of human growth hormone treatment for 1 to 7 years on the growth of 100 children with growth hormone deficiency, low birth weight, inherited smallness, Turner's syndrome, and other complaints. Arch Dis Child. 46:745-782.

14. Grunt JA, Enriquez AR, Daughaday WH, Budd S. 1972 Acute and long-term responses to hGH in children with idiopathic small-of-dates dwarfism. J Clin Endocrinol Metab. 35:157-168.

15. Stanhope R, Preece MA, Hamill G. 1991 Does growth hormone treatment improve final height attainment of children with intrauterine growth retardation? Arch Dis Child. 66:1180-1183.

16. Albanese A, Stanhope R. 1993 Growth and metabolic data following growth hormone treatment of children with intrauterine growth retardation. Horm Res. 39:8-12.

17. Chatelain P, Job JC, Blanchard J, et al. 1994 Dose-dependent catch-up growth after 2 years of growth hormone treatment in intrauterine growth retarded children. J Clin Endocrinol Metab. 78:1454-1460.

18. Job JC, Chaussain JL, Job B, et al. 1996 Follow-up of three years of treatment with growth hormone and of one post-treatment year, in children with severe growth retardation of intrauterine onset. Pediatr Res. 39:354-359.

19. Chaussain JL, Colle M, Landier F. 1994 Effects of growth hormone therapy in prepubertal children with short stature secondary to intrauterine growth retardation. Acta Paediatr Scand. 399(Suppl):74-75.

20. de Zegher F, Maes M, Gargosky SE, et al. 1996 High-dose growth hormone treatment of short children born small for gestational age. J Clin Endocrinol Metab. 81:1887-1892.

21. Boguszewski M, Albertsson-Wikland K, Aronsson S. 1998 Growth hormone treatment of short children born small-for-gestational-age: the Nordic Multicentre Trial. Acta Paediatr. 87:257-263.

22. de Zegher F, Butenandt O, Chatelain P, et al. 1997 Growth hormone treatment of short children born small for gestational age: reappraisal of the rate of bone maturation over 2 years and metanalysis of height gain over 4 years. Acta Pediatr. 423(Suppl):207-212. 
23. Usher R, MacLean F. 1969 Intrauterine growth of liveborn caucasian infants at sea level: standard obtained from measurements of infants born between 25 and 44 weeks of gestation. J Pediatr. 74:901-910.

24. Roede MJ, Van Wieringen JC. 1985 Growth diagrams 1980, Netherlands. Third nation-wide survey. T Soc Gezondheidsz. 63(Suppl):1-34.

25. Rikken B, Wit JM. 1992 Prepubertal height velocity references over a wide age range. Arch Dis Child. 67:1277-1280.

26. Tanner JM, Whitehouse R. 1976 Longitudinal standards for height, weightheight, height velocity and stages of puberty. Arch Dis Child. 51:170-179.

27. Cameron N. 1978 The methods of auxological anthropometry. In: Falkner F, Tanner JM, eds. Human growth. London: Tindall; vol 2:35-87.

28. Tanner JM, Whitehouse RH, Cameron N, Marshall WA, Healy MJR, Goldstein H. 1983 Assessment of skeletal maturity and prediction of adult height (TW2-method), 2nd Ed. London: Academic Press.

29. de Waal WJ. 1996 Influencing the extremes of growth, PhD thesis. Erasmus University, Rotterdam, The Netherlands.

30. Hokken-Koelega ACS, Hackeng WHL, Stijnen Th, Wit JM, de Muinck Keizer-Schrama SMPF, Drop SLS. 1990 Twenty-four-hour growth hormone (GH) profiles, urinary GH excretion, and plasma insulin-like growth factor-I and -II levels in prepubertal children with chronic renal insufficiency and severe growth retardation. J Clin Endocrinol Metab. 71:688-695.

31. Blum WF, Ranke MB, Kietzmann K, Gauggel E, Zeisel HJ, Bierich JR, 1990 A specific radioimmunoassay for the growth hormone $(\mathrm{GH})$-dependent somatomedin-binding protein: its use for diagnosis GH deficiency. J Clin Endocrinol Metab. 70:1292-1298.

32. Van Teunenbroek A de Muinck Keizer-Schrama SMPF, Stijnen T, et al. 1993 Effect of growth hormone administration frequency on 24-hour growth hormone profiles and levels of other growth related parameters in girls with Turner's syndrome. Clin Endocrinol (Oxf). 39:77-84.

33. Hokken-Koelega ACS, Stijnen T, de Muinck Keizer-Schrama SMPF, Blum WF, Drop SLS. 1993 Levels of growth hormone, insulin-like growth factor-I (IGF-I) and -II, IGF-binding protein-1 and -3, and cortisol in prednisonetreated children with growth retardation after renal transplantation. J Clin Endocrinol Metab. 11:932-939.
34. Rikken B, van Doorn J, Ringeling A, Van den Brande JL, Massa G, Wit JM. 1998 Plasma levels of insulin-like growth factor (IGF)-I, IGF-II and IGF-binding protein-3 in the evaluation of childhood growth hormone deficiency. Horm Res. 50:166-176.

35. de Zegher F, Francois I, van Helvoirt M, Beckers D, Ibáñez L, Chatelain P. 1998 Growth hormone treatment of short children born small for gestational age. Trends Endocrinol Metab. 9:233-237.

36. Tanner JM, Lejarraga H, Cameron N. 1975 The natural history of the SilverRussell syndrome: a longitudinal study of thirty-nine cases. Pediatr Res. 9:611-623.

37. Davies PSW, Valley R, Preece MA. 1988 Adolescent growth and pubertal progression in the Silver-Russell syndrome. Arch Dis Child. 63:130-135.

38. Ranke MB, Lindberg A. 1996 Growth hormone treatment of short children born small for gestational age or with Silver-Russell syndrome: results from KIGS (Kabi International Growth study), including the first report on final height. Acta Paediatr. 417(suppl):18-26.

39. Albanese A, Azcona C, Stanhope R. 1998 Final height in children with IUGR receiving GH treatment. Horm Res. 50(Suppl 3):46.

40. Azcona C, Albanese A, Bareille P, Stanhope R. 1998 Growth hormone treatment in growth hormone-sufficient and -insufficient children with intrauterine growth retardation/Russell-Silver syndrome. Horm Res. 50:22-27.

41. Hofman PL, Cutfield WS, Robinson EM, et al. 1997 Insulin resistance in short children with intrauterine growth retardation. J Clin Endocrinol Metab. 82:402-406.

42. Barker DJ, Hales CN, Fall CH, Osmond C, Phipps K, Clark PM. 1993 Type 2 (non-insulin- dependent) diabetes mellitus, hypertension and hyperlipidaemia (syndrome X): relation to reduced fetal growth. Diabetologica. 36:62-67.

43. van der Reijden-Lakeman IEA. 1996 Growing pains? PhD thesis. Erasmus University, Rotterdam, The Netherlands.

44. van der Reijden-Lakeman IEA, Slijper FME, van Dongen-Melman JEWM, de Waal WJ, Verhulst FC. 1996 Self-concept before and after two years of growth hormone treatment in intrauterine growth-retarded children. Horm Res. 46:88-94. 